\title{
RANCANG BANGUN EKSPERIMEN SEDERHANA KUAT MEDAN MAGNET MENGGUNAKAN SENSOR KECEPATAN ARDUINO
}

\author{
Iman Safari ${ }^{\text {a) }}$, Inggrid Ayu Putri ${ }^{\text {b) }}$, Riris Purbosari ${ }^{\text {c) }}$, Rita Amalia Huljannah ${ }^{\text {d) }}$, \\ Iwan Sugihartono $^{\mathrm{e})}$, Mangasi Alion Marpaung ${ }^{\mathrm{f})}$
}

Program Magister Pendidikan Fisika, Fakultas Matematika dan Ilmu Pengetahuan Alam, Universitas Negeri Jakarta, Rawamangun, Jakarta Timur, DKI Jakarta, Indonesia 13220

Email: : ${ }^{\text {a) }} \underline{\text { iman.safari@globalprestasi.sch.id }},{ }^{\text {b) }}$ inggrida41@ gmail.com, ${ }^{\text {c) }}$ ritirispurbosari13@ @ gmail.com,

\begin{abstract}
Abstrak
Pada pembelajaran Induksi elektromagnet, pada umumnya siswa SMA kelas XII mampu menyebutkan faktor-faktor yang mempengaruhi tegangan GGL. Salah satu faktor yang disebutkan adalah memperbesar kuat medan magnet yang digunakan. Tetapi 93,7\% memiliki analisis bahwa kuat medan magnet berhubungan dengan ukuran magnet. Di dalam penelitian ini akan dilakukan pembuatan rancang bangun eksperimen sederhana untuk menentukan kuat medan listrik. Eksperimen bertujuan untuk memberikan alternatif percobaan yang bisa memberikan pengalaman langsung kepada siswa sehingga dapat memecahkan masalah miskonsepsi siswa tentang kuat medan magnet. Penelitian ini menggunakan metode ADDIE (analyse, design, development, Implementation, dan Evaluation). Namun, penelitian ini hanya dilakukan sampai tahap develeopment. Hasil dari sensor akan dipresentasikan dalam grafik tegangang GGL terhadap kecepatan sudut putarnya digrafikkan sehingga dapat dihitung besar kuat medan magnet yang ada.
\end{abstract}

Kata-kata kunci: kuat medan magnet, sensor kecepatan, arduino.

\begin{abstract}
In learning electromagnetic induction, high school students in grade 12 are generally able to mention the factors that influence the voltage of electromotive force. One of the factors mentioned is to increase the strength of the magnetic field used. But $93.7 \%$ had an analysis that the magnetic field strength was related to the size of the magnet. In this study it will be reported about the design of simple experiments to determine the electric field strength. The research aims to provide an alternative experiment which gives direct experience to students so that they can solve the problem of students' misconceptions about magnetic field strength. The results of the sensors will be presented in the graph of the GLD strain on the rotational angular velocity so that the magnitude of the magnetic field can be calculated.
\end{abstract}

Keywords: Magnetic field strength, velocity sensor, arduino 


\section{PENDAHULUAN}

Ilmu Fisika adalah ilmu yang empiris, yang didasarkan pada gejala-gejala yang terjadi dan dapat diamati dengan indera. Oleh karenanya dalam pembelajaran mata pelajaran fisika disertai dengan pengamatan gejala atau percobaan di laboratorium yang di dalamnya juga dilakukan pengukuran. Jika kebiasaan mengamati gejala fisika melalui pengamatan langsung di dalam kelas, aktivitas di laboratorium atau bahkan melalui pengamatan gejala dalam kehidupan jarang dilakukan, maka akan ada potensi masalah bagi siswa dalam memahami pokok bahasan yang dipelajari. Apalagi jika materi yang dipelajari adalah hal yang abstrak. Salah satu gejala dan hal abstrak yang jarang diamati dan dilakukan dalam pembelajaran di kelas adalah cara pengukuran kuat medan magnet [2]. Pengukuran kuat medan magnet pada kawat berarus [3] dan pada pokok bahasan tegangan GGL [6]

Medan magnet adalah fenomena fisik yang berkaitan dengan kuantitas listrik. Arus listrik menciptakan medan magnet, dan sebaliknya arus listrik dapat dihasilkan dari magnet yang digerakkan di dekat kumparan kawat. Untuk mengetahui besarnya dan arah, medan magnet perlu dilakukan pengukuran. Medan magnet dinyatakan dalam satuan Tesla, misalnya, magnet bumi normal bidang di dekat khatulistiwa sekitar 45.000 nano Tesla, dengan arah utara-selatan [6]. Kuat medan magnet merupakan salah satu besaran fisika yang sangat penting adalah medan magnet dan untuk mengukur kuat medan magnet diperlukan sensor magnetik [6].

Sensor magnetik sering digunakan dan diaplikasikan dalam berbagai bidang, seperti industri, rumah tangga, kesehatan, dan lain-lain. Hal ini disebabkan karena penggunaan sensor magnetik memiliki banyak kelebihan diantaranya adalah linieritasnya, kestabilannya tinggi, tidak merusak (non destruktif), sensitivitas yang tinggi, relatif sederhana, biaya operasi yang murah dan relatif mudah untuk menggunakannya [1]. Berbagai macam jenis dari sensor magnetik telah banyak dikembangkan, salah satunya adalah efek sensor magnetik aula. Sensor ini dirancang untuk merasakan keberadaan objek magnetik dengan perubahan posisi. Perubahan medan magnet yang terus menerus menyebabkan terjadinya pulsa yang kemudian dapat ditentukan frekuensinya, sensor jenis ini biasa digunakan sebagai pengukur kecepatan[6].

Saat ini proses pembacaan data sensor magnetik yang mudah menjadi suatu keharusan. Hal ini berkaitan dengan perkembangan ilmu pengetahuan dan teknologi dalam memenuhi kebutuhan manusia, terutama yang terkait dengan perangkat elektronik. Hampir setiap peralatan listrik dari peralatan rumah tangga hingga alat komunikasi bereaksi terhadap medan elektromagnetik.[6].

Untuk memudahkan pembacaan data sensor magnetik, terdapat beberapa alternatif lain yang sudah ditawarkan dalam pengukuran kuat medan magnet. Diantaranya yaitu pengukuran kuat medan magnet dari batang magnet menggunakan sensor smartphone [8]. Pengukuran kuat medan magnet pada kawat melingkar dan kawat lurus dengan menggunakan sensor kuat medan magnet pada smartphone [5]. Percobaan-percobaan yang dengan menggunakan smartphone memerlukan spesifikasi smartphone tertentu, karena tidak semua smartphone dilengkapi dengan sensor kuat medan magnet. Dengan adanya keterbatasan-keterbatasan di atas, penelitian ini menawarkan alternatif pengukuran kuat medan magnet dengan melakukan pengamatan kecepatan putar motor listrik sederhana menggunakan sensor kecepatan infra merah FC-03 LM 393 yang dihubungkan dengan interface Arduino Mega 2560.

Arduino merupakan platform pembuatan prototipe elektronik yang bersifat open-source hardware, berdasarkan pada perangkat keras dan lunak yang mudah dan feksibel untuk digunakan [9]. Arduino hadir untuk mengkonverter data dari analog ke digital (A/D) [7], dan ia mempunyai beberapa kelebihan diantaranya memiliki bahasa pemograman yang relatif mudah, dan modul yang siap pakai [4]. Ia memiliki misi untuk membuat teknologi menjadi mudah diakses oleh siapapun, termasuk dalam genggaman semua guru dan pendidik. Untuk memungkinkan hal tersebut telah diciptakan Arduino Education sebagai sebuah dedikasi dari tim global yang terdiri dari ahli pendidikan, pengembang kurikulum, para insinyur dan desainer interaktif [10]. 


\title{
METODOLOGI
}

Penelitian ini menggunakan metode Research and Development (R\&D) tipe ADDIE. Addie terdiri dari Analyse, Design, Development, Implementation, dan Evaluation. Namun, pada penelitian ini hanya dilakukan sampai tahap Development. Penelitian ini akan menggunakan lilitan dengan jumlah tertentu yang dihubungkan dengan sumber tegangan listrik. Di sekitar lilitan akan ditempatkan magnet neodymium dengan ukuran tertentu. Kecepatan perputaran motor akan diamati dengan menggunakan sensor inframerah yang akan dihubungkan dengan perangkat Ardiuno Mega dan ditampilkan dalam display. Dengan mengubah besar tegangan listrik, maka akan mengubah kecepatan putar motor.

Data hasil pengamatan akan ditampilkan dalam kecepatan putar bentuk grafik antara terhadap tegangan listrik. Dengan mengukur luas simpal secara manual dan menentukan jumlah lilitan simpal, maka gradien tegangan listrik terhadap kecepatan putar dapat diamati sebagai persamaan (1) berikut ini.

$$
\begin{gathered}
\text { gradient }=N \times B \times A \\
\varepsilon=\text { gradient } . \omega \\
\text { where gradient }=\mathrm{N} \mathrm{B} \mathrm{A} \\
\frac{1}{\text { gradient }}=\frac{\omega}{\varepsilon}
\end{gathered}
$$

Dengan menggunakan lilitan yang sama, maka nilai $\mathrm{N}$ dan A dapat dianggap sebagai konstanta. Dengan membandingkan nilai 1/gradien-nya maka kita akan menemukan perbandingan nilai kuat medan magnetnya.

\section{HASIL DAN PEMBAHASAN}

\begin{abstract}
Analyse
Pada tahap analisis dilakukan analisis kebutuhan menggunakan angket secara online menggunakan Google Form agar memudahkan untuk mengambil data dari berbagai wilayah. Siswa yang di jangkau adalah siswa SMA Kelas XII. Penyebaran angket ini dimaksudkan untuk mengetahui apakah para siswa di sekolah-sekolah, khususnya dalam penelitian ini pada wilayah Jakarta dan Bekasi menerima praktikum materi fisika Magnet di kelas menggunakan kit praktikum medan magnet. Materi medan magnet untuk sekolah menengah atas dipelajari di kelas XII. Dari survey yang telah dilakukan dengan melibatkan 16 responden siswa kelas 12 di Bekasi dan Jakarta, didapat hanya $12.5 \%$ yang mengaku pernah melakukan pengamatan dan pengukuran kuat medan magnet secara langsung dengan menggunakan tesla meter yang memang belum tentu dimiliki oleh semua Laboratorium di sekolah menengah di Indonesia. Dari data tersebut dapat diartikan bahwa pengalaman yang diterima oleh siswa dalam pengukuran kuat medan magnet masih terbatas. Selama ini pengamatan di laboratorium sekolah menengah atas hanya sebatas mengamati gejala garis medan magnet di sekitar kawat berarus maupun di sekitar magnet, itupun tidak semua sekolah melakukannya karena adanya keterbatasan waktu, keterbatasan alat dan sebagainya.
\end{abstract}

\section{Design}

Pada tahap design, penelitian ini melakukan rancangan kit praktikum medan magnet seperti pada GAMBAR 1 berikut ini. 


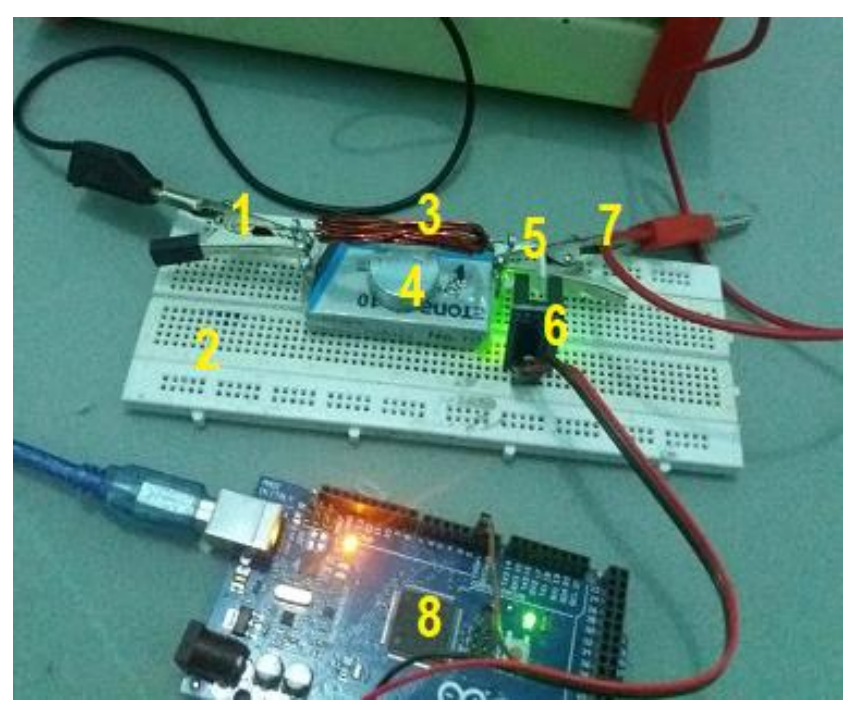

1. Connector to Power Supply (Ground)

2. Protoboard

3. Coil

4. Neodymium Magnet

5. Kipas

6. Speed sensor FC-03 LM 393

7. Connector to Power Supply (+)

8. Ardiuno Interface Program

GAMBAR 1. Skema alat dalam pengukuran kecepatan (rpm) motor listrik DC sederhana

\section{Development}

Pada tahap pengembangan, dilakukan uji coba alat untuk menghasilkan data hasil uji coba alat. Pada percobaan ini digunakan motor yang sama (dengan jumlah lilitan dan luas permukaan yang sama) sehingga faktor jumlah lilitan dan luas permukaan dapat dijadikan konstanta. Dengan membandingkan gradien garis dari grafik putaran vs tegangan maka dapat diketahui perbandingan kuat medan magnet dari kedua jenis magnet yang digunakan. Pada percobaan juga perlu memperhatikan jarak antara magnet dengan lilitan untuk mendapatkan data yang lebih valid. Percobaan dilakukan dengan menggunakan 2 variasi ukuran magnet neodimium yang berbeda.

Data hasil sensor ditampilkan dalam bentuk angka dalam layar komputer menggunakan perangkat lunak Ardiuno display monitor COM5. Pada percobaan dengan menggunakan gabungan 3 magnet berdiameter $20 \mathrm{~mm}$ dan tinggi $0.15 \mathrm{~mm}$ dan tegangan 8 volt diperoleh data sebagai berikut.

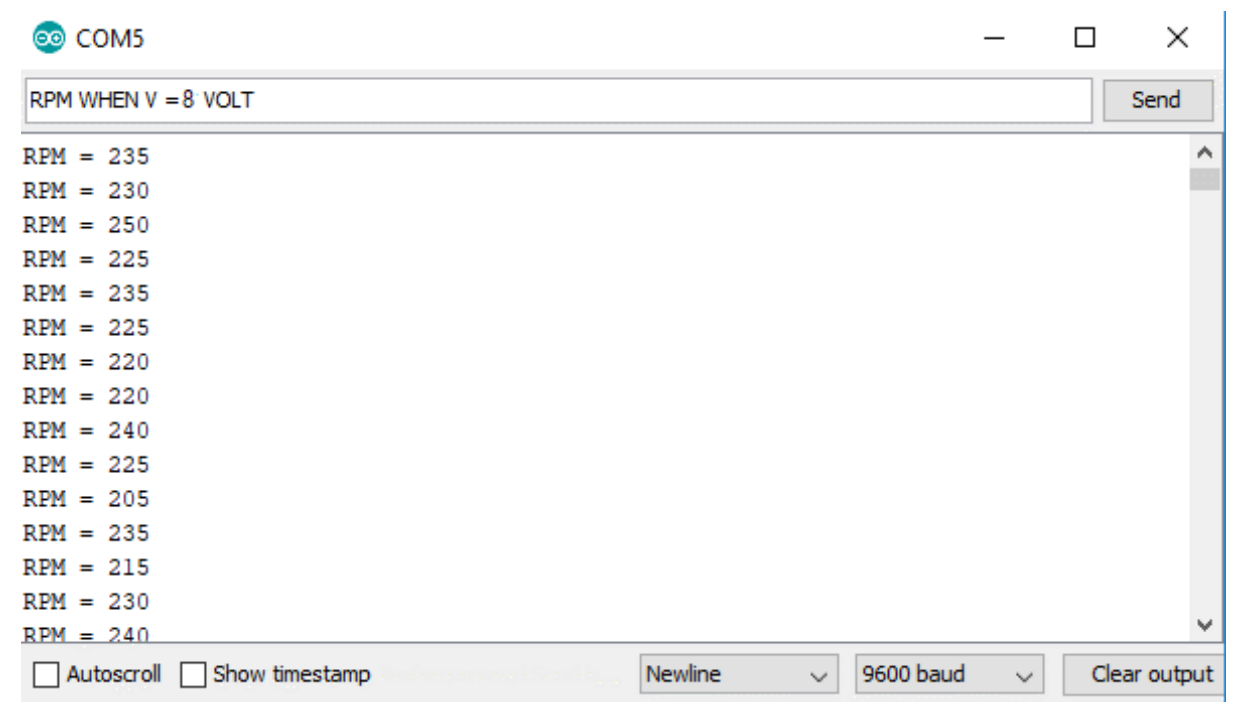

GAMBAR 2. Data pengukuran RPM

Dari data grafik diperoleh data yang fluktuatif, ini berkaitan dengan gerak motor listrik yang kurang stabil. Percobaan dengan menggunakan magnet dengan ukuran yang lebih besar (magnet 
neodymium dengan diameter $25 \mathrm{~mm}$ dan tinggi $0.5 \mathrm{~mm}$ ) pada tegangan yang sama (8 Volt) memunculkan perputaran yang tidak stabil, bahkan kadang-kadang menjadi short circuit. Dari gejala tersebut, maka data diambil jika perputaran mulai stabil dan digunakan tegangan listrik 2,4 dan 6 volt saja.

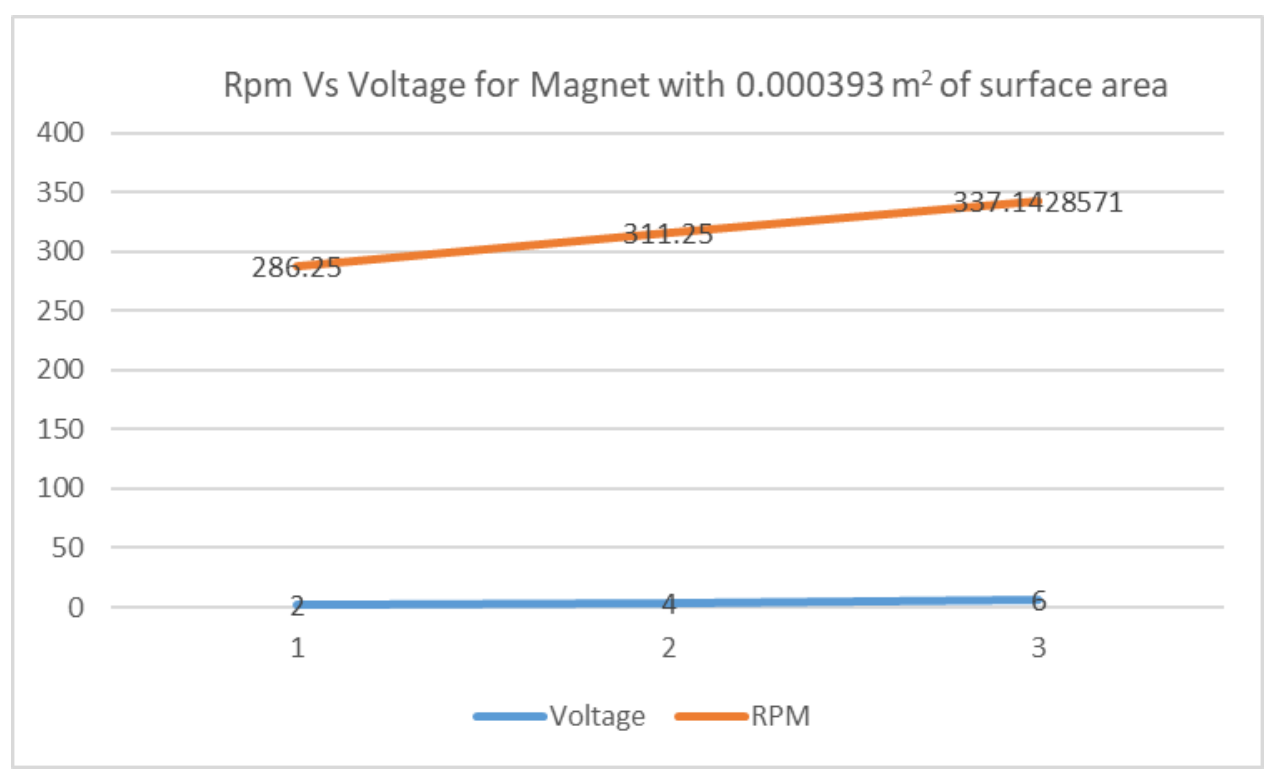

GAMBAR 3. Kecepatan dalam Rpm berbanding tegangan untuk luas permukaan magnet yang lebih besar

Dari data grafik yang ditampilkan gambar 3, diperoleh gradien grafik $=(337.1428571$ $286.25) / 3=16.96429$. Kuat medan magnet $\mathrm{x}$ konstanta berbanding terbalik dengan gradien $=1 /$ $16.96429=0.058947$.

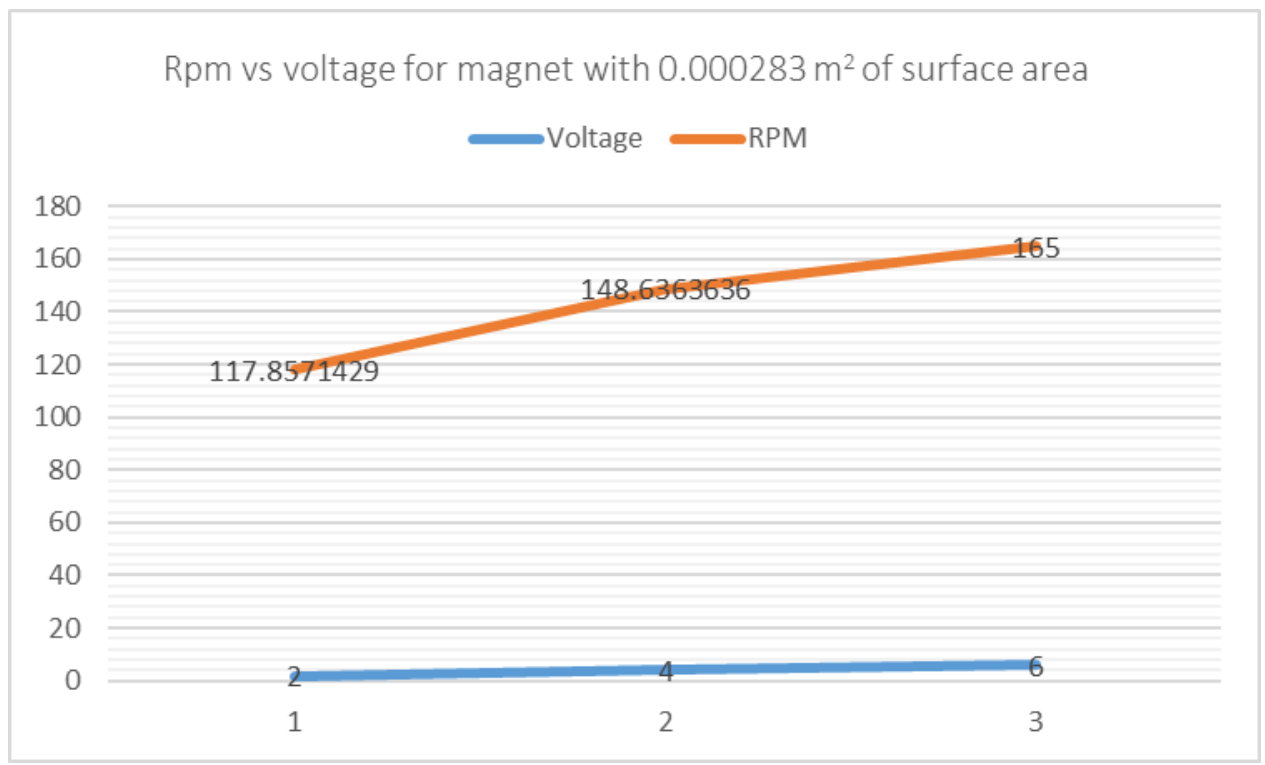

GAMBAR 4. Kecepatan dalam Rpm berbanding tegangan untuk area permukaan magnet yang lebih kecil

Dari data grafik pada gambar 4 diperoleh gradien grafik $=(165-117.8571429) / 3=15.71429$. Kuat medan magnet $\mathrm{x}$ konstanta berbanding terbalik dengan gradien $=1 / 15.71429=0.063636$ Karena menggunakan jenis motor yang sama dan 2 jenis magnet yang berbeda, maka dengan membandingkan data 1/gradien kedua grafik di atas, kita dapat membandingkan kuat medan magnet 
yang dihasilkan kedua magnet yang digunakan. Percobaan dengan menggunakan ukuran magnet yang lebih kecil didapatkan gradien yang lebih kecil, Dengan membandingkan hasil nilai 1/ gradiennya, maka perbandingan kuat medan antara kedua magnet yaitu,

$$
\frac{B_{\text {smaller magnet }}}{B_{\text {bigger magnet }}}=\frac{\frac{1}{\text { graph gradient smaller magnet }}}{\frac{1}{\text { graph gradient for nigger magnet }}}=\frac{0.063636}{0.058947}=1.079545
$$

Percobaan dengan menggunakan ukuran magnet yang lebih besar didapatkan gradien yang lebih besar, sehingga nilai 1/gradien-nya lebih kecil dibandingkan percobaan dengan menggunakan magnet yang lebih kecil. Ini membuktikan bahwa ukuran magnet tidak selalu sebanding dengan kuat medan magnetnya. Dalam percobaan ini belum dilakukan percobaan dengan jenis bahan magnet yang berbeda tetapi berbeda ukuran.

Pengukuran kuat medan magnet yang digunakan dengan cara ini memang terkesan lebih rumit daripada sekedar hanya menampilkan data dengan menggunakan smartphone. Tetapi pengukuran ini dapat menambah beberapa ketrampilan siswa, diantaranya; keterampilan mengamati, ketrampilan memecahkan masalah dan ketrampilan mem-plot grafik dan keterampilan menginterprestasi grafik. Perlu dibandingkan efektifitas pengukuran kuat medan magnet dengan cara ini dengan pengukuran yang menggunakan tesla meter yang tersedia dalam handphone.

\section{Evaluation}

Pada tahap evaluasi, penelitian ini melakukan beberapa revsi pada produk, karena pada tahap pengembangan atau development terdapat uji coba alat yang tidak berfungsi sebagaimana mestinya. Oleh karena itu, penelitian ini beberapa kali memperbaiki alat sampai menemukan hasil yang seharusnya. Evaluasi ini dilakukan disetiap tahapan untuk mendapatkan hasil yang maksimal.

\section{SIMPULAN}

Percobaan dengan pengukuran kuat medan magnet dengan menggunakan sensor kecepatan pada motor listrik sederhana dapat dijadikan sebagai alat peraga pembelajaran untuk materi medan magnet. Penelitian ini masih perlu diselidiki perbandingan efektivitas metode ini dengan metode yang lain.

\section{REFERENSI}

[1] Suryono, Riyanti, A., \& Suseno, J. E. (2009). Karakterisasi Sensor Magnetik Efek Hall UGN3503 Terhadap Sumber Magnet dan Implementasinya pada Pengukuran Massa. Berkala Fisika, 1-9.

[2] Singh1, J. L. (2017). Developing and validating a conceptual survey to assess introductory physics students' understanding of magnetism. European Journal of Physics , 1-25.

[3] Siska Desy Fatmaryanti, S. S. (2017). Attainment of students' conception in magnetic fields by using of direct observation and symbolic language ability. International Conference on Science and Applied Science 2017, 1-6.

[4] Silvia, A. F., Haritman, E., \& Muladi, Y. (2014). Rancang bangun akses kontrol pintu gerbang berbasis arduino dan android. Electrans, 1-10. 
[5] R D Septianto, D. a. (2017). Utilisation of the magnetic sensor in a smartphone for facile magnetostatics experiment: magnetic field due to electrical current in straight and loop wires. Physics Education Journal, 1-7.

[6] Kristina Zuza, M. (2016). University students' understanding of the electromotive force concept in the context of electromagnetic induction. European Journal of Physics, 1-13.

[7] Fatmaryanti, S. D., Al Hakim, Y., \& Ashari. (2018). Comparative study of magnetic fields measurements with logger lite and Arduino on electronic devices. International Conference on Engineering and Applied Technology (ICEAT), 1-7.

[8] Al-Taani, S. A. (2017). Measuring the Earth's magnetic field dip angle using a smartphoneaided setup: a simple experiment for introductory physics laboratories. European Journal of Physics, 1-9.

[9] Arifin, J., Zulita, L. N., \& Hermawansyah. (2016). Perancangan murottal otomatis menggunakan mikrokontroller arduino mega 2560. Jurnal Media Infotama, 89-98.

[10]Ardiuno. (2019, 6 22). Education. Retrieved from https://www.arduino.cc: https://www.arduino.cc/en/Main/Education 
